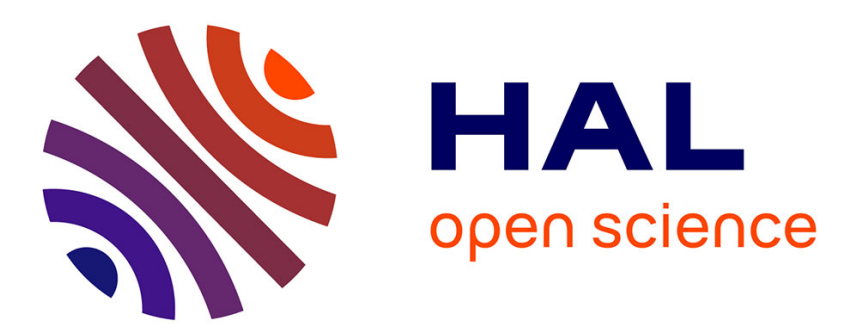

\title{
On the relationship between the formation factor and diffusion coefficients of Portland cement mortars
}

\author{
Z. Bajja, W. Dridi, B. Larbi, P. Le Bescop
}

\section{To cite this version:}

Z. Bajja, W. Dridi, B. Larbi, P. Le Bescop. On the relationship between the formation factor and diffusion coefficients of Portland cement mortars. ICCRRR - 4th International Conference on Concrete Repair, Rehabilitation and Retrofitting, Oct 2015, Leipzig, Germany. cea-02509264

\section{HAL Id: cea-02509264 https://hal-cea.archives-ouvertes.fr/cea-02509264}

Submitted on 16 Mar 2020

HAL is a multi-disciplinary open access archive for the deposit and dissemination of scientific research documents, whether they are published or not. The documents may come from teaching and research institutions in France or abroad, or from public or private research centers.
L'archive ouverte pluridisciplinaire HAL, est destinée au dépôt et à la diffusion de documents scientifiques de niveau recherche, publiés ou non, émanant des établissements d'enseignement et de recherche français ou étrangers, des laboratoires publics ou privés. 


\title{
On the relationship between the formation factor and diffusion coefficients of Portland cement mortars
}

\author{
Z. Bajja ${ }^{\text {a }}$, W. Dridi ${ }^{\text {a }}$, B. Larbi ${ }^{\text {a }}$, P. Le Bescop ${ }^{\text {a }}$ \\ ${ }^{a}$ CEA, DEN, DPC, SECR, Laboratoire d'Etude du Comportement des Bétons et des Argiles, F-91191 Gif-sur- \\ Yvette, France
}

\begin{abstract}
Concrete durability continues to be a subject of considerable interest, especially with the use of cement based materials on structures increasingly demanding on term of sustainability and resistance to aggressive ions penetration or radionuclide release. Diffusion is considered one of the main transport phenomena that cause migration of aggressive solutes and radionuclide in a porous media according to most studies.

In this work, two different tracers (an ion, and a radionuclide) were tested on the same formulations of mortars ( $\mathrm{w} / \mathrm{c}=0,4$ and sand volume fractions from 0 to $60 \%$ ) by the through-out diffusion, in order to determine the effective diffusion coefficients of each tracer and each formulation. The obtained results have proven the validity of the formation factor equation relating the effective diffusivity of a tracer to its diffusion coefficient in pure water.
\end{abstract}

\section{INTRODUCTION}

Despite the significant efforts deployed to improve the design, production and placement of concrete mixtures, the premature decay of infrastructures remains one of the main challenges facing the construction industry at the beginning of this 21 st century [1]. Therefore, the durability of cement-based materials continues to receive significant international attention from both scientists and engineers.

Since these materials are porous, their durability is basically determined by their ability to resist the penetration and the transport of aggressive agents. The diffusion coefficients of ions and radionuclides in cementitious materials are the most important parameters to evaluate the state of degradation of structures.

In the framework of the storage of nuclear waste, (HTO) the liquid form of tritium, is considered as an ideal tracer for the characterization of the effective diffusivity in cementitious materials, because of its negligible interaction with the cement matrix [2] and the facility to apply Fick's law to a molecule such the HTO. However, the radioactive nature of HTO encourages looking for nonradioactive elements (generally ions) that can provide its diffusion coefficient without having to carry out tritiated water diffusion tests very expensive and dangerous.
Only diffusion in saturated porous materials is concerned in this study. Electro-diffusion and unsaturated conditions are ignored hereafter. Thus, the aim of this study is to prove the validity of the formation factor equation (Eq. 1) relating the effective diffusivity $\left(\mathrm{D}_{\mathrm{e}}{ }^{\text {ion }}, \mathrm{D}_{\mathrm{e}}{ }^{\mathrm{rad}}\right)$ in the cementitious material respectively of an ion and a radionuclide to their diffusion coefficient $\left(\mathrm{D}_{0}{ }^{\text {ion }} ; \mathrm{D}_{0}{ }^{\text {rad }}\right)$ in an infinitely diluted solution, usually in pure water at $25^{\circ} \mathrm{C}$.

$$
F=\frac{D_{0}^{r a d}}{D_{e}^{r a d}}=\frac{D_{0}^{i o n}}{D_{e}^{i o n}}
$$

For that purpose, several formulations of mortars were tested in through-out diffusion with HTO and with lithium ion which has allowed identifying their diffusion coefficients.

\section{EXPERIMENTAL PROCEDURES}

\subsection{Test program}

Six different mixtures were prepared, to achieve the goal fixed previously. Mortars were manufactured from mixing Portland cement (European grade CEM I 52, 5 N CE PM-ESCP2 NF), with standardized siliceous sand CEN IN 196-1 labeled SN, and with water and the super plasticizer Glenium 27 for some formulations. 
These formulations were made by fixing water-tocement ratio $(\mathrm{w} / \mathrm{c})$ and by varying the relative aggregate volume content $\left(\mathrm{C}_{\mathrm{ag}}\right)$ in the objective to have different geometrical formation factors for each specimen. . (Table 1) gives the proportions of the tested materials.

Table 1: Proportions of materials tested

\begin{tabular}{c|ccc}
\hline Mixtures ID & $w / c^{(1)}$ & $C_{a g}{ }^{(2)}$ & Gle-27 \\
\hline SN. 0\% & 0.4 & $0 \%$ & -- \\
SN. 10\% & 0.4 & $10 \%$ & -- \\
SN. 30\% & 0.4 & $30 \%$ & -- \\
SN. 50\% & 0.4 & $50 \%$ & -- \\
SN. 55\% & 0.4 & $55 \%$ & -- \\
SN. 60\% & 0.4 & $60 \%$ & $0.5 \%$ \\
\hline
\end{tabular}

(1) $\mathrm{w} / \mathrm{c}$ is the water-to-cement ratio.

(2) $\mathrm{C}_{\mathrm{ag}}$ is the relative aggregate volume content

(3) Gle-27(\%) is the weight of Glenium 27 relative to weight of cement

Mortar specimens were mixed according to the standard mortar fabrication procedure NF EN 196-1 and were cast in PVC cylinders $70 \mathrm{~mm}$ in diameter and $110 \mathrm{~mm}$ high.

After $24 \mathrm{~h}$, specimens were demoulded and conserved in lime water. They were cured in a humid chamber at $\mathrm{T}=20 \pm 1^{\circ} \mathrm{C}$ for a period exceeding three months, to ensure complete hydration of the material and to have a "fixed" microstructure during all the experiments.

Samples used for diffusion tests are $6 \mathrm{~mm}$ thick discs, obtained by underwater cutting of the central portion of each specimen. The thickness chosen for discs of $6 \mathrm{~mm}$ is justified for two reasons: First, a reason of representativeness, because to have reliable results, the sample must at least have a thickness three times larger than the maximum grain diameter $(1,8 \mathrm{~mm}$ for $\mathrm{SN})$. Also, a thick sample will take more time to be tested by the through-out diffusion than a fine sample. That's why, the thickness of $6 \mathrm{~mm}$ was chosen since it represents a compromise between the rapidity and the representativeness of the test.

\subsection{Microstructure analysis:}

The microstructure of the studied materials was investigated by free water porosity and Mercury Intrusion Porosimetry (MIP) measurements.

\subsubsection{Free water porosity measurements:}

Water porosity measurement is considered as a parameter of first order in the evaluation of the durability of material [3]. The experimental method [4] consists in determining water porosity by weighing the three following parameters: The sample water satu- rated mass $M_{s}$, the sample dried mass $M_{D}$, and $M_{w}$ the sample mass when immersed in water.

Dried mass was obtained after an oven drying at the temperature of $60^{\circ} \mathrm{C}$ until constant weight. From these data, porosity accessible to water can be calculated as follows:

$$
\phi=\frac{M_{s}-M_{D}}{M_{s}-M_{w}}
$$

\subsubsection{Mercury intrusion porosimetry:}

Before testing, the samples were first frozen ($195^{\circ} \mathrm{C}$ ) by immersion into liquid nitrogen for $5 \mathrm{~min}$. This quick quenching process at very low temperature allows generation of ice microcrystals that do not alter the microstructure.

After freezing, samples were introduced for 7 days in a freeze-dryer in which vacuum were kept to 10-1 $\mathrm{Pa}$. This operation allows the ice trapped in the material porosity to sublimate. This freeze-drying technique is commonly used in many industrial areas like soil engineering, food industry, and biology. This technique is considered as a suitable procedure for MIP investigation on cement-based materials [5, 6]. MIP measurements have been carried out using micromeritics porosimeter with a maximum $413 \mathrm{MPa}$ injection pressure. The contact angle was $130^{\circ}$ for all samples. The minimum pore access diameter reached is about $3 \mathrm{~nm}$. For each specimen, two samples were tested and the results averaged.

\subsection{Through-out diffusion tests}

There are many methods of measurement of the coefficients of diffusion. Most known are natural diffusion tests, electrically accelerated tests or test of immersion in a concentrated solution. The choice of the method of measurement depends on the nature of the diffusing element but also on requirements of time. For this study the choice of the diffusing element will be on one hand a radioactive isotope (HTO) and on the other hand a solution containing lithium ions $\mathrm{Li}^{+}$( lithium chloride solution $\mathrm{LiCl}$ ) .

The through-out diffusion tests consist on putting the mortar sample between two compartments. The samples were sealed into position using an epoxy adhesive "Araldite" and by means of O-rings to avoid leakage.

Each compartment of $111 \pm 1 \mathrm{ml}$ volume is filled with saturated lime water. Then the cell is left to stand for about fifteen days to check the tightness of the cell and stabilize the sample before the test. After 
this period, the upstream compartment of each cell was doped with one of two species (HTO or $\left.\mathrm{Li}^{+}\right)$.

The amount of elements transferred from the upstream to the downstream compartment was then followed in time by successive samplings which were analyzed by ionic chromatography device (for monitoring $\mathrm{Li}^{+}$ions) and by a scintillation tritium monitor for the monitoring of HTO. The lower limit of detection for the ionic chromatography is $0.18 \mu \mathrm{mol} / 1$.

During the test, the concentration at the downstream compartment was checked not to reach $3 \%$ of the upstream concentration; otherwise, the downstream solution is drained. Therefore the upstream concentration $\mathrm{C}_{0}$ and downstream one $\mathrm{C}_{1}$ were maintained constant for all time $\left(\mathrm{C}_{0}=3.210^{6} \mathrm{~Bq} / \mathrm{L} ; \mathrm{C}_{1} \approx 0\right)$ for HTO and $\left(\mathrm{C}_{0}=41 \mathrm{mmol} / \mathrm{l} ; \mathrm{C}_{1} \approx 0\right)$ for lithium solution $(\mathrm{LiCl})$.

\section{RESULTS}

\subsection{Water porosity and mercury intrusion porosimetry:}

By increasing the sand content in mortars, the water porosity decreases (Figure 1a).Water porosities are then compared to $\left(1-\mathrm{C}_{\mathrm{ag}}\right)$ linear plot called the law of perfect dilution and which reflects the linear decrease of mortars porosity made with non-porous aggregates. It can be seen that experimental results are close to $\left(1-\mathrm{C}_{\mathrm{ag}}\right)$ plot and don't breached the line except for the SN.60\% mortar where water porosity value is slightly above dilution line.

This was confirmed by measurements of bulk densities by water porosimetry (Figure $1 b$ ). The evolution according to the sand content curve presents a fall of the density at the SN.60\%.

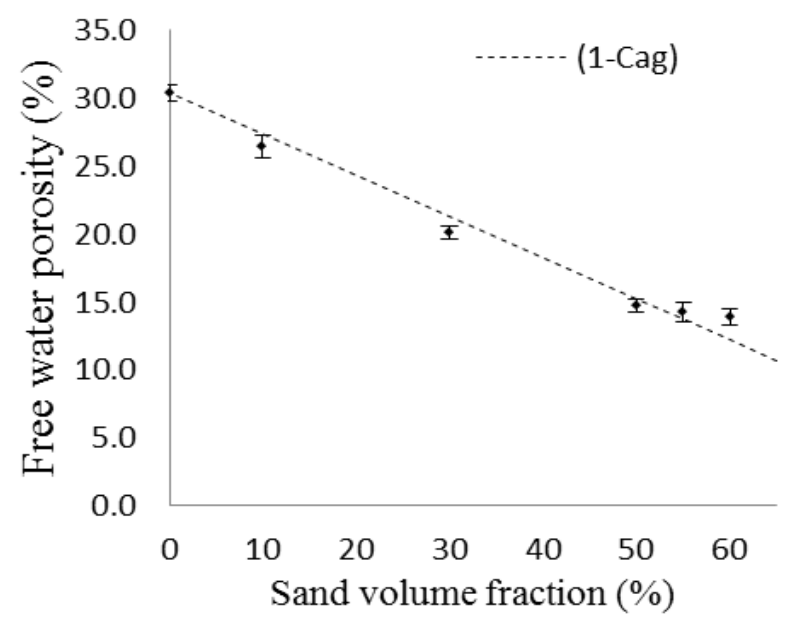

Figure 1a: Results of free water porosity measurements for tested mortars

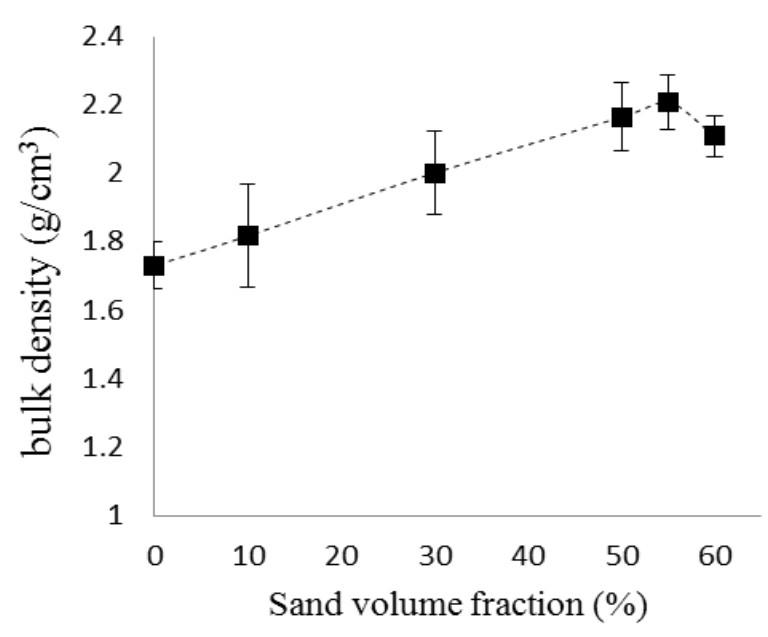

Figure 1b: Results of bulk density measurements for tested mortars

The slight increase of porosity and the decrease of bulk density in $60 \%$ sand volume fraction are correlated with an increase in air voids content within the material. Voids which can be interpreted by the presence of air bubbles. This anomaly of the SN.60\% was also observed by mercury porosimetry. Figure 2 presents the pore size distribution of the tested formulations.

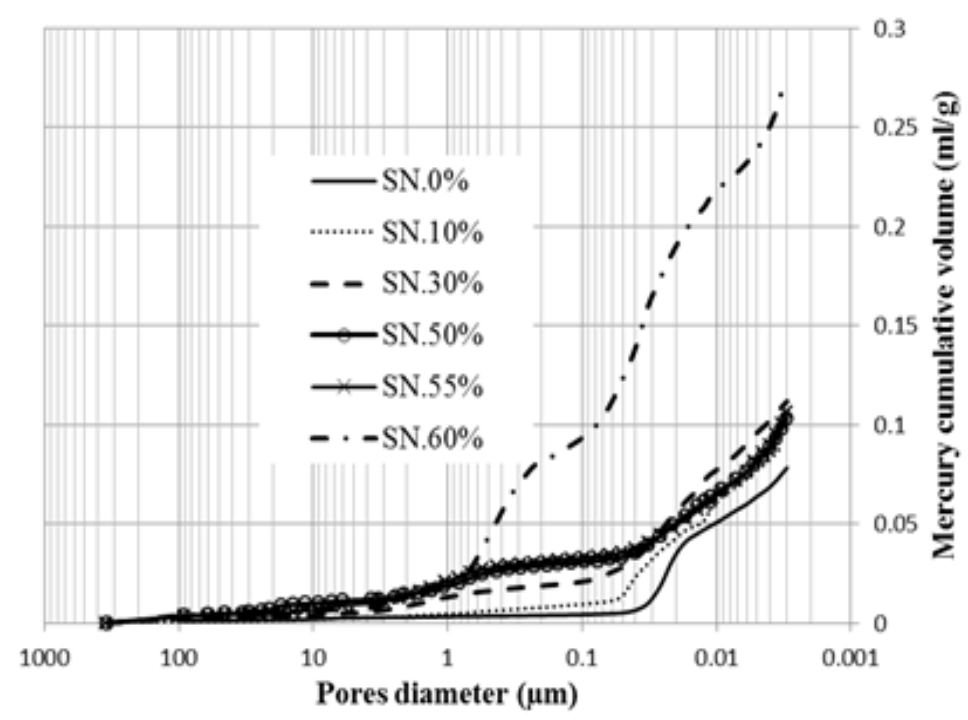

Figure 2: Pore size distribution of tested mortars

The curve representing the cement paste (SN.0\%) shows that the diameter of the largest pores appears around $0,05 \mu \mathrm{m}$, a threshold diameter from which percolation of capillary pores is observed. In contrast, the curves corresponding to the other formulations show that the pore distribution is characterized in particular by the appearance of larger diameters than those observed for cement paste. The addition of aggregates therefore increases the amount of larger pores $(\geq 0,01 \mu \mathrm{m})$, even for mortars with only $10 \%$ of sand. This change in microstructure may be due to the formation of Interface Transition Zone aggregates 
/ paste (ITZ) characterized by a higher porosity and its percolation $[7,8,9]$. However, this explanation is not sufficient to justify the microstructural behavior of (SN.60\%) mortar.

\subsection{Diffusion tests}

\subsubsection{Lithium diffusivity in mortars}

(Figure 3) shows the profile of effective diffusion coefficients of lithium ion vs. the sand volume fraction present in the formulations.

It is noticed, that with low content of sand in particular between 0 and $50 \%$, the diffusivity of lithium decreases with sand content in a perfect dilution law :

$$
D_{e}^{\text {mortar }}=D_{e}^{\text {paste }} \times\left(1-C_{a g}\right)
$$

With $D_{e}{ }^{\text {mortar }}$ is the diffusion coefficient of the mortar, $\mathrm{D}_{\mathrm{e}}{ }^{\text {paste }}$ the diffusion coefficient of the cement paste, and $\mathrm{C}_{\mathrm{ag}}$, the sand content in the mortar.

Mortar behavior becomes different starting from the formulation SN. 55\%, where the diffusion coefficient varies very little compared to the mortar within $50 \%$ sand content. However, the formulation which remains the most significant is SN.60\%, because its diffusion coefficient rises considerably and largely exceeds the diffusion coefficient of the cement paste.

These results observed for different formulations are in perfect agreement with the results of water porosity and mercury porosimetry. These phenomena were also noted in previous studies found in the literature such [10] and [11].

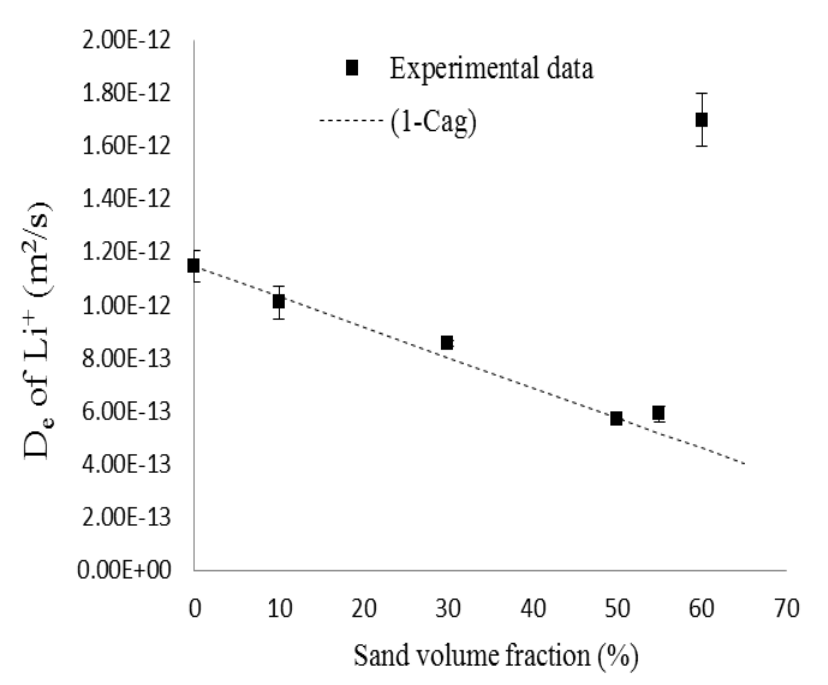

Figure 3: Effective diffusion coefficient $D_{e}$ vs sand content of lithium

\subsubsection{Tritiated water diffusivity in mortars}

Tritium diffusion tests were carried out on the formulations SN. $0 \%$, SN. $10 \%$, SN. $30 \%$, SN. $50 \%$ and SN. $60 \%$ and were repeated twice for each formulation. Both formulations SN. 55\% and SN. 65\% could not be tested by tritium diffusion.

(Figure 4) shows the effective diffusion coefficient values according to aggregate fraction volume. The general tendency of the curve in figure 4 is in perfect agreement with the diffusion results of lithium and with water porosity and mercury porosimetry results.

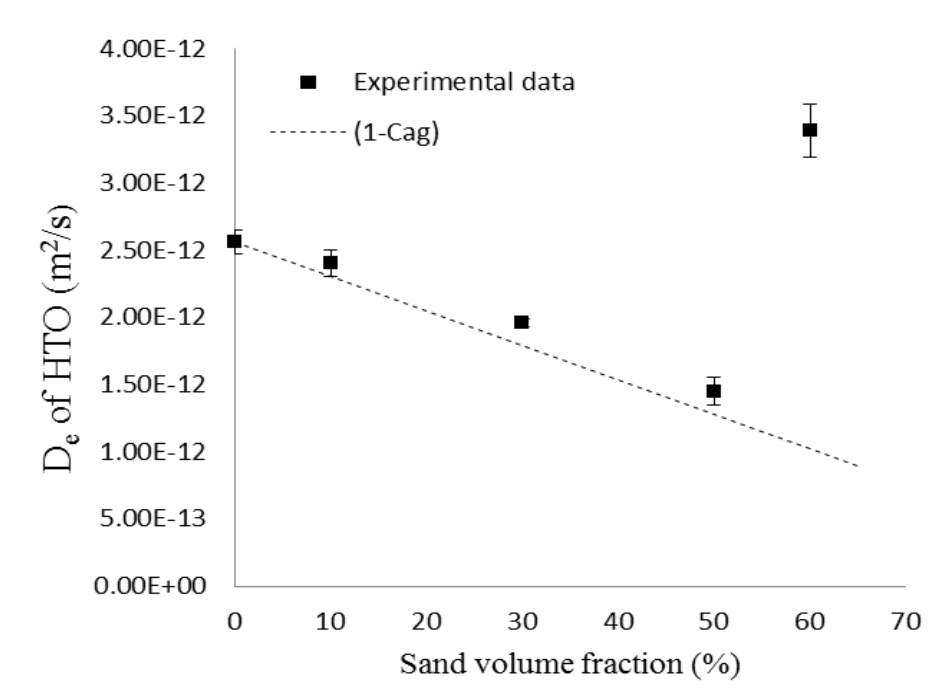

Figure 4: Effective diffusion coefficient $\mathrm{D}_{\mathrm{e}}$ of $\mathrm{HTO}$ vs sand content in mortars

\subsubsection{Interpretation of diffusion results :}

For materials with less than 55\% sand volume, the effect of dilution is dominating for the two tests of diffusion with HTO and lithium. In these formulations, the ITZ layer around the aggregates exists according to the results of mercury porosimetry, but it remains isolated and does not affect diffusive characteristics of the materials.

This tendency has suddenly changed from 55 to $60 \%$ sand volume fraction, where a significant increase in the diffusion coefficient is observed. Moreover, il was noticed an increase in the mercury penetrated volume (at $0.6 \mu \mathrm{m}$ diameter in Figure 2) revealing of the interconnection of this class of pores $(0.1$ to $1 \mu \mathrm{m})$. This interconnection created can therefore cause the formation of a percolation path within the sample which may justify this very significant increase in diffusivity. In this case, several hypotheses can be suggested to try to explain the cause of this interconnection. Among these, the interconnection of ITZ and / or the heterogeneity of the material. This 
last proposition means that because of the small proportion of cement present in the SN. $60 \%$, it is possible to find some areas poor in cement but rich in water, others containing sufficient binder, and another part that may contain anhydrous in majority.

These various material microstructures can finally lead us to believe that a competitive aspect exist in mortars: on one side, the presence of nonporous sand grains tend to decrease the diffusivity but on the other the presence and the interconnectivity of ITZ are respectively at the origin of the appearance of larger pores and probably the cause of the increase of the diffusion coefficient (in the SN. 60\%).

\section{DISCUSSION ON THE VALIDITY OF THE FORMATION FACTOR CONCEPT}

The objective of this paragraph is to compare the formation factors obtained experimentally from the results of lithium and tritium diffusion tests.

(Table 3) shows experimental values of effective diffusion coefficients of each tracer within the tested formulations. Therefore, knowing the diffusion coefficients of the element " $\mathrm{i}$ " $\left(D_{0}^{i}\right)$, it is possible to calculate the formation factor for each formulation using the relation:

$$
F_{i}=\frac{D_{0}^{i}}{D_{e}^{i}}
$$

It is noted that the values of $\mathrm{D}_{0}{ }^{\mathrm{HTO}}$ et $\mathrm{D}_{0}{ }^{\mathrm{Li}}$ measured in an infinitely diluted solutions are respectively $2.27 \times 10^{-9}\left(\mathrm{~m}^{2} / \mathrm{s}\right)$ and $1.03 \times 10^{-9}\left(\mathrm{~m}^{2} / \mathrm{s}\right)[12]$.

Table 3: Experimental diffusion coefficients and resulting formation factors

\begin{tabular}{ccccc}
\hline Mixtures ID & $\mathbf{D}_{\mathrm{e}}{ }^{\mathrm{HTO}}\left(\mathbf{m}^{2} / \mathbf{s}\right)$ & $\mathbf{D}_{\mathrm{e}}^{\mathrm{Li}}\left(\mathbf{m}^{2} / \mathbf{s}\right)$ & $\boldsymbol{F}_{\boldsymbol{H T O}}$ & $\boldsymbol{F}_{\boldsymbol{L} i}$ \\
\hline SN. 0\% & $2.56 .10^{-12}$ & $1.15 .10^{-12}$ & 886.72 & 896.43 \\
\hline SN. 10\% & $2.40 .10^{-12}$ & $1.01 .10^{-12}$ & 945.83 & 1019.80 \\
\hline SN. 30\% & $1.96 .10^{-12}$ & $8.55 .10^{-13}$ & 1158.16 & 1204.67 \\
\hline SN. 50\% & $1.45 .10^{-12}$ & $5.69 .10^{-13}$ & 1565.52 & 1810.19 \\
\hline SN. 55\% & --- & $5.90 .10^{-13}$ & --- & 1745.76 \\
\hline SN. 60\% & $3.39 .10^{-12}$ & $1.70 .10^{-12}$ & 669.62 & 605.88 \\
\hline
\end{tabular}

The comparison between experimental formation factors gives rather close results, (Figure 5).

Initially, formation factors (of HTO and lithium) follow the same tendency i.e. they increase with the sand content for mortars until $55 \%$ of sand, and decrease dramatically around $60 \%$ of sand.

Disparities between formation factor values measured with the two tracers do not exceed $15 \%$ for all tested formulations except the SN.60\% mortar where a difference of about $25 \%$ is recorded. Regarding an uncertainty of measurements around $20 \%$ in the diffusion tests, the obtained results make it possible to validate the (Eq.1). They confirm the geometrical character of the formation factor which reflects the morphology and the connectivity of pore network of a given material. They also reveal the invariability of this parameter regarding the nature and the concentration of diffusing tracer.

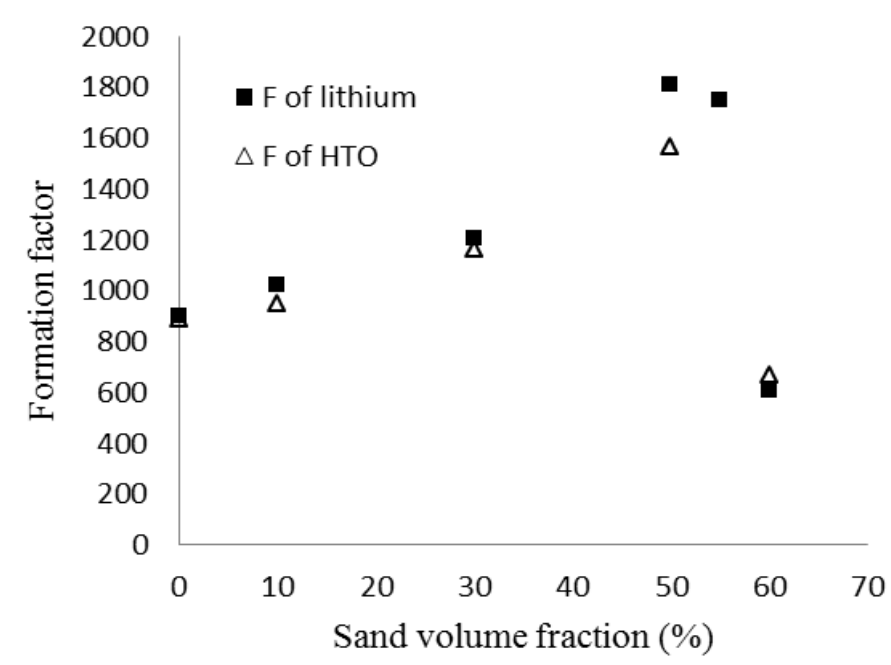

Figure 5: Comparison between formation factor of lithium, and HTO obtained experimentally

Differences obtained between these factors must normally tend to zero since it is the same formulations which were tested by the two tracers. Because of some disturbances that can take place during tests, such an error exists. Among these disturbing factors, may be mentioned two possible reasons. From one perspective, it was noticed during the tests, a slight drop of temperature in the room where were placed the cells, this fall of temperature can cause a decrease in effective diffusion coefficients and thus increase the formation factor F. From another perspective, the increase in the formation factor may be due to the presence of chlorides ions in the upstream solution (solution of $\mathrm{LiCl}$ ). These ions diffusing into mortars can involve some possible modifications in the microstructure of materials, in particular in the porosity of the hydrates. Otherwise, since hydrates porosity in CEM I based materials represents a smaller fraction of total porosity (compared to a CEM V material for example), the effect produced by chloride ions on the 
geometry of pores cannot be more important. In addition the concentration of chlorides ions used is quite weak, and the duration of which analyses were stopped (113 days) remain insufficient to cause modifications in the microstructure of the samples. This effect was noticed by [13] mainly for concretes containing CEMV, where the variation of formation factors is more considerable.

Finally, the omission of electrical interaction between diffusing species (ions) can also explain the disparities between formation factors obtained from HTO and ionic species diffusion tests.

\section{CONCLUSION}

With the assessment of this paper, several conclusions could be found. First, it was shown that the Eq. 1 - giving the expression of diffusion coefficients of any ionic or radioactive specie from the geometrical formation factor of a material - can be validated for at least the two species tested which are lithium ion and tritiated water. This validity is conditioned by the respect of tests conditions i.e. a rather low upstream concentration of $41 \mathrm{mmol} / \mathrm{l}$ of $\mathrm{LiCl}$, a fixed temperature during diffusion tests, materials formulated only with CEM I and without additions... This result is regarded as perfectly interesting, since it will allow determining orders of magnitude of the effective diffusion coefficients of any other diffusing specie by knowing the geometrical formation factor of a material. However, to determine the formation factor, it is preferable to use tritium as a tracer, because its low reactivity with the cementing matrix, but also because it diffuses more quickly than ions (steady state starts at 10 days for HTO against 30 days for lithium ion) and thereafter, makes it possible to have the exact value of De for shorter tests durations compared to ions.

\section{REFERENCES}

[1] J.F. Young, Bridging concrete into the 21st century Proceedings of the ECI Conference on Advances in Cement and Concrete, August 21-24, Copper Mountain, CO (2003), pp. $1-8$.

[2] C. Richet, Etude de la migration des radioéléments dans les liants hydrauliques - Influence du vieillissement des liants sur les mécanismes et la cinétiques des transferts, Ph.D. Thesis; Université Paris XI Orsay (1992) (in French).

[3] V. Baroghel-Bouny \& Ammouche A. (2007). Sous groupe « microstructure ». In Arliguie \& Hornain (Dir), Grandubé book (pp. 63-106) (in French).

[4] Grandubé book - Grandeurs associés à la durabilité des bétons - French association of civil engineering (2007)
[5] C. Gallé, Effect of drying on cement-based materials pore structure as identified by mercury intrusion porosimetry, a comparative study between oven-, vacuum-, and freezedrying, Cem. Concr. Res. 31 (2001) 1467-1477

[6] A. Kumar, D.M. Roy, The effect of desiccation on the porosity and pore structure of freeze-dried hardened Portland cement and slag blended pastes, Cem. Concr. Res. 16 (1) (1986) 74- 78 .

[7] B. Bourdette, E. Ringot, J.P. Ollivier, Modelling of the transition zone porosity, Cem. Concr. Res. 25 (1995) 741-751.

[8] D.N. Winslow, M.D. Cohen, D.B. Bentz, K.A. Snyder, E.J. Garboczi, Percolation and pore structure in mortars and concrete, Cem. Concr. Res. 24 (1994) 25-37.

[9] S. Caré, Influence of aggregates on chloride diffusion coefficient into mortar, Cem. Concr. Res. 33 (2003) 10211028.

[10] B. Bourdette, Prise en compte des aureoles de transition dans la characterisation et la modélisation des processus physique et chimiques d'altération, Ph.D. Thesis, Institut National des Sciences Appliqués de Toulouse (1994) (in French).

[11] E.J. Garboczi, D.P. Bentz, Modelling of the microstructure and transport properties of concrete, Cem. Concr. Res. 10 (1996), 293 - 300.

[12] P. Vanysek ; Ionic Conductivity and Diffusion at Infinite Dilution - CRC Hansbook of Chemestry and Physics, 2000- 203.158.253.140.

[13] H.R. Mercado Mendoza, Transferts aqueux à travers les matériaux cimentaires partiellement saturés. Ph.D. Thesis ; University of Toulouse (2012) in French. 